\title{
First report of white root disease of Artocarpus nobilis in Sri Lanka caused by Rigidoporus microporus
}

\author{
H.K.I. Madushani ${ }^{1}$, T.H.P.S. Fernando ${ }^{1 *}$, R.L.C. Wijesundara ${ }^{2}$ and D. Siriwardane ${ }^{1}$ \\ ${ }^{1}$ Department of Plant Pathology and Microbiology, Rubber Research Institute of Sri Lanka, Dartonfield, Agalawatta. \\ ${ }^{2}$ Department of Plant Sciences, Faculty of Science, University of Colombo, Colombo 03.
}

Revised: 27 December 2013; Accepted: 24 January 2014

Keywords: Artocarpus nobilis, Hevea brasiliensis, pathogenicity, rhizomorphs, Rigidoporus microporus.

Artocarpus nobilis (family Moraceae) is an economically important endemic tree common in the Wet Zone, the mid-country homesteads and the Wet Zone forests in Sri Lanka. Its seeds are edible, the wood is used in construction industry and the boiled fruit is a substitute for rice.

Two Artocarpus nobilis trees with symptomatic white root disease patches (Figure 1) were observed in the vicinity of rubber plantations in the Kalutara District (Western Province) of Sri Lanka. The initial foliar symptoms were the development of a slight offgreen colour. Later the leaves turned yellowish brown. At advanced stages, the affected leaves turned brown and eventually fell off resulting in a die-back of the affected branches. On the roots, whitish, profusely branched rhizomorphs were visible. The rhizomorphs were firmly attached to the surface of the roots and later turned pale yellow. Thereafter, the rhizomorphs advanced to the collar region.

Isolations were made on malt extract agar (MEA) from symptomatic $A$. nobilis roots after surface sterilization with $0.01 \% \mathrm{HgCl}_{2}$ for $2 \mathrm{~min}$. Pure cultures were derived from hyphal tip isolations carried out through microscopic observations. The cultures were maintained on MEA at room temperature $\left(28 \pm 2{ }^{\circ} \mathrm{C}\right)$. The mycelial growth on MEA was flat and the lower surface had an off-white colour. The upper surface was pure white. The fungus was identified as Rigidoporus microporus, which is the causative fungus of the white root disease of Hevea brasiliensis (Jayasinghe \& Wettasinghe, 1996; Kaewchai et al., 2010). The identification was based on cultural morphology of the colonies and thereafter artificial inoculation of rubber root pieces produced the characteristic bracket shaped basidiocarps.

Pathogenicity tests were performed using healthy A. nobilis saplings (five months old) grown in pots. To prepare the artificial inocula, fresh root pieces of A. nobilis ( $8 \mathrm{~cm}$ long) were washed thoroughly under running tap water to remove soil particles adhering to the surface. Thereafter, $8 \mathrm{~cm}$ long root pieces were cut, soaked in distilled water for 1 hour and autoclaved for $45 \mathrm{~min}$ at $121{ }^{\circ} \mathrm{C}$ in $500 \mathrm{~mL}$ glass beakers covered with tin foil. Rigidoporus microporus isolated from $A$. nobilis grown on MEA was used for inoculation. Three agar blocks $\left(4 \mathrm{~cm}^{2}\right)$ from the advancing margin of the above cultures were transferred aseptically into the surface of autoclaved roots in the beakers and incubated for 6 weeks at room temperature $\left(28 \pm 2{ }^{\circ} \mathrm{C}\right)$. Four months old ten $A$. nobilis saplings raised under greenhouse conditions at the Rubber Research Institute of Sri Lanka were artificially inoculated (Fernando et al., 2012) using the inocula prepared as given above. After four months of incubation, the symptoms produced were noted (well grown rhizomorphs on the roots and a partial rot at the collar region) and they were similar to the symptoms observed earlier. The fungus was re-isolated on to MEA from the roots of the artificially inoculated seedlings. The cultural characteristics of the re-isolated fungus were similar to the original isolate.

Pathogenicity of the isolates on seedlings of Hevea 


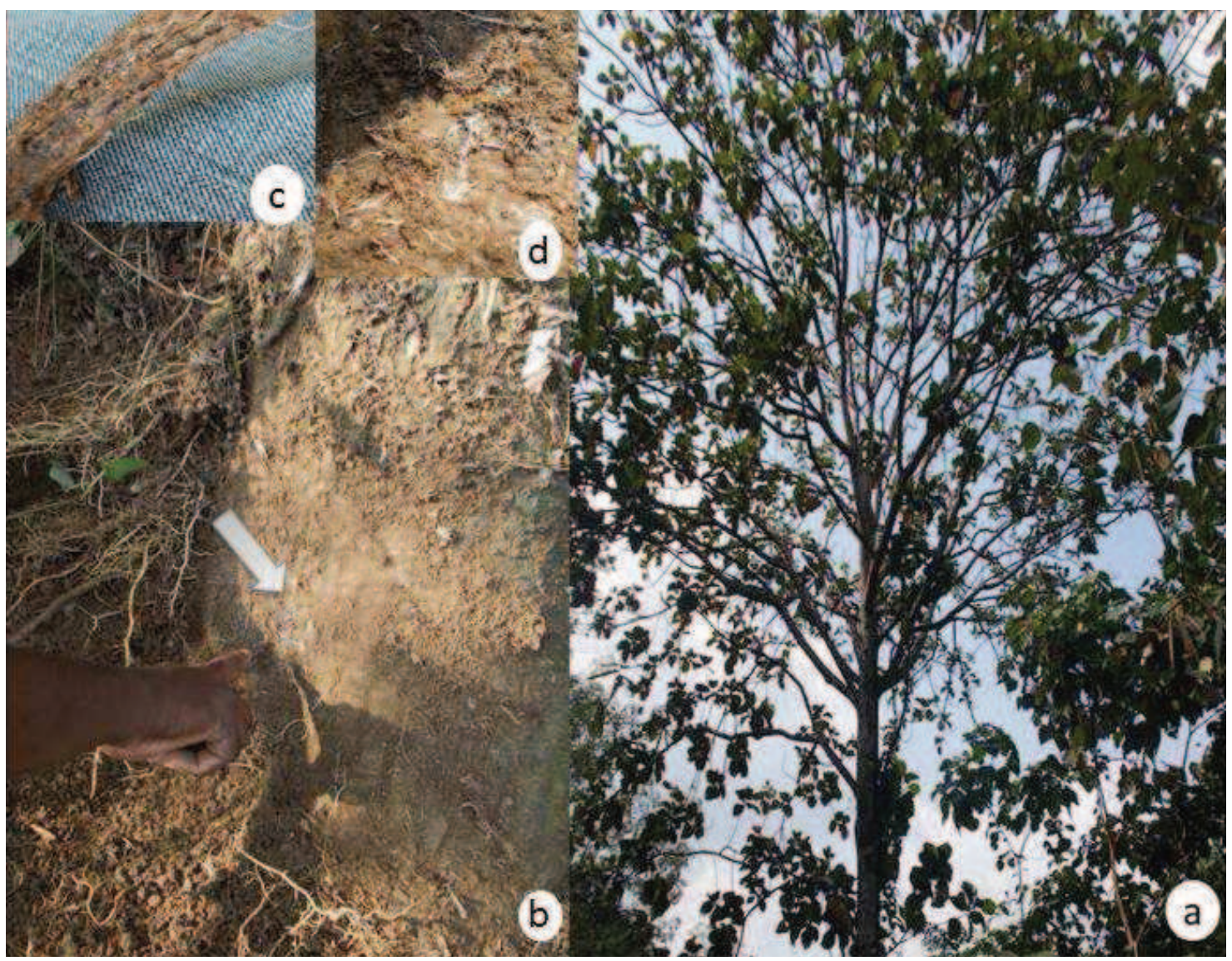

Figure 1: White root disease on Artocarpus nobilis. a) Symptomatic plant showing yellowing and wilting symptoms. b) The collar region of the affected plant. Note the whitish fungal threads. c) Infected root piece to show the rhizormorphs. d) Growth of the fungi on the collar region: a close up.

brasiliensis was also investigated using potted rubber seedlings (Fernando et al., 2012). Fourty rubber seedlings were used for cross inoculation studies. After six months of incubation, the rubber seedlings showed the established rhizormophs with slightly discoloured leaves. The A. nobilis isolate of $R$. microporus was also pathogenic on $H$. brasiliensis. To our knowledge, this is the first published report of $R$. microporus infecting Artocarpus nobilis in Sri Lanka and elsewhere.

\section{Acknowledgement}

Authors gratefully acknowledge the financial assistance from the National Research Council, Sri Lanka (Grant 11-39).

\section{REFERENCES}

1. Fernando T.H.P.S., Jayasinghe C.K., Wijesundara R.L.C. \& Siriwardane D. (2012). Development of an early detection method for white root disease caused by Rigidoporus microporus. Proceedings of the International Forestry and Environment Symposium 17: 94.

2. Jayasinghe C.K. \& Wettasinghe J.L.P.C. (1996). Saprophytic colonization of Geotrichum sp. on Hevea brasiliensis roots, a condition that resembles white root disease. Journal of the Rubber Research Institute of Sri Lanka 78: 102 - 103.

3. Kaewchai S., Lin F.C., Wang H.K. \& Soytong K. (2010). Characterization of Rigidoporus microporus isolated from rubber trees based on morphology and ITS sequencing. Journal of Agricultural Technology 6(2): 289 - 298. 